\title{
Knowledge, Perception and Attitude Regarding Generic Medicines among Iraqi Physicians
}

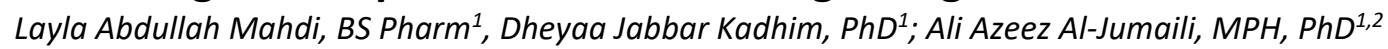

${ }^{1}$ University of Baghdad College of Pharmacy, Baghdad, Iraq; ${ }^{2}$ The University of lowa College of Pharmacy, Iowa, USA

\begin{abstract}
Objectives: The study aim was to explore the knowledge, perceptions, and attitudes of Iraqi physicians regarding generic and locally manufactured medicines.

Methods: A total of 124 physicians were involved in this cross -sectional study. The convenience sample was collected from five public hospitals in Baghdad. A self-administered questionnaire was distributed and collected in-person. Fisher's Exact Test was used to measure the association between physician years of experience, gender and categorical (perception and knowledge) variables.

Results: Most respondent answers regarding the knowledge of generic medicines were incorrect. Only up to one-third of the participants knew that generic medicines are therapeutically equivalent to brand name medicines (26.6\%), as safe as brand name medicines (34.7\%) and required to meet similar safety standards as brand name medicines (12.1\%). With respect to perception, many physicians had negative perceptions about generic medicines such as viewing generic medicines as lower quality (57.3\%) and cause more side effects (41.1\%) compared to brand name medicines. Regarding physician attitudes toward generic medicines, about twothirds (64.5\%) of the physicians were willing to prescribe low cost medicines; however, only about half (51.6\%) of the physicians reported they offer generic medicines to their patients. Finally, 64.5\% of the participants were not comfortable with pharmacist replacing prescribed brand with generic medicines.
\end{abstract}

Conclusions: In general, Iraqi physicians have negative perceptions and attitudes about generic and locally manufactured medicines. Significant gaps were identified in the knowledge and perceptions among physicians regarding generic medicines especially in relation to efficacy and safety of generic medicines.

Keywords: Physicians, knowledge, attitude, perceptions, generic medicines

\section{Introduction}

The US Food and Drug Administration (FDA) defines generic medicines as a medication that is comparable to brand listed medication in dosage form, strength, route of administration, quality and performance characteristics, and intended use (1). A brand-name drug is a drug that has a trade name and is protected by a patent. When the patent protection of a brandname drug expires, generic versions of the drug can be offered for sale (2). A generic drug is a proven bioequivalent to the innovator brand, where both deliver the active ingredient to the blood stream at the same rate and to the same extent (3). Under the FDA's regulations, a generic medicine must contain identical amount of the same active ingredients in the same dosage form as a brand name medicine (4).

Generic medicines are generally less expensive than their brand-name counterparts. Generic drugs typically cost $30 \%$ to $60 \%$ less than their brand-name counterparts (5). Global healthcare expenditure is increasing steadily, and generic

Corresponding author: Ali Azeez Al-Jumaili, MPH, PhD University of Baghdad College of Pharmacy, Baghdad, Iraq Adjunct Assistant Professor, University of lowa College of Pharmacy, lowa, USA; Email: aliazeezali-aljumaili@uiowa.edu medicine utilization is often encouraged as a cost-containment measure (5)(6). In addition, patients taking generic drugs appear to be more compliant than those taking brand-name medications. Lower copayment is a key factor (7). Many doctors oppose brand substitution and believe generic medicines to be inferior to their branded counterparts (8). Physician perceptions about generic drugs may affect their acceptance of generic drugs. According to a recent systematic review, about one-quarter of physicians and pharmacists expressed negative perceptions about the safety and side effects of generic medicines (8). In the UK, there was strong opposition when plans were proposed to introduce generic substitution into UK primary care (9).

As the main prescribers of medicines in Iraqi healthcare settings, physicians have an essential role in recommending generic medicines for patients. Generally, Iraqi private healthcare settings do not implement health insurance and patients should pay physician visit fees and medication costs out of pocket. At present, there is no reimbursement system for money spent by the public on prescriptions from community pharmacies in the country. Many families with limited income cannot afford the cost of brand name medicines. Thus, ensuring the availability of high-quality medicines at affordable prices in Iraq is a public health priority (10). 
To the best of our knowledge, this was the first study quantitatively assessed physician knowledge, perceptions and attitudes toward generic medicines. The aim of the current study was to explore the knowledge, perceptions, and attitudes of physicians regarding generic and locally manufactured medicines in Baghdad.

\section{Methods}

Design and Settings: This was a cross sectional study carried out during the four months from April to August 2019. The convenience sample was collected from five public hospitals across Baghdad and its suburb (Baghdad Teaching Hospital, AlYarmouk Teaching Hospital, Al-Numan Teaching Hospital, Ibn Al-Baitar Teaching Hospital and Abu Ghraib Hospital) which represent the main hospitals in both sides of the province.

Participants: Physicians from all specialties were included if they had a private clinic and were willing to participate in the study. The study selected physicians practicing in private clinic because physicians in the private sector (clinics) have more prescribing choices and flexibility compared to the public (governmental) sector. The study included physicians working at morning shift from any specialties who had a private clinic and agreed to participate. After obtaining the consent from the physicians, a paper self-administered questionnaire was distributed and collected in-person.

Survey: We adopted the survey items from Jamshed et al, 2012 study (11). Thus, the survey items were already validated. The questionnaire consisted of four parts. The first part included sociodemographic of the participating physicians. The second part included 12 statements and addressed the physician knowledge about interchangeability, safety, quality and efficacy of generic medicines. The third part included 14 statements and addressed the physician perceptions about safety, quality and efficacy of generic medicines. The fourth part included 12 statements and evaluated the attitude of physicians towards generic medicine prescribing considering the socioeconomic condition of the patient, patients' demands, and influence of medical representatives. Knowledge domains have response categories of yes/no. Perception and attitude domains have response categories on Likert scale: $3=$ Agree, 2=Neutral, 1=Disagree (11).

Ethical approval: The study proposal was approved by the Ethical and Scientific committee at University of Baghdad College of Pharmacy.

\section{Statistical analysis}

The analyses were conducted using the Statistical Package for the Social Science (SPSS, version 22, IBM, New York, USA). Descriptive statistics (means, standards deviations, frequencies and percentages) of the participants were calculated. Fisher's Exact Test was used to measure the association between physician years of experience and gender from one side and perception and knowledge variables from other side. The answers for knowledge questions were yes, no, I do not know. "I do not know' answers were also considered incorrect as a previous study conducted in the Netherlands (12). Perception and attitude questions had 3-points Likert scale answers (disagree, neutral, agree). A p-value $<0.05$ was considered statistically significant.

\section{Results}

A total of 124 physicians (85 male and 39 female) were involved in this study. The age range of physicians was 28-62 years with a mean of $39.2 \pm 6.1$ years. The demographics and professional characteristics of the participating physicians are shown in table 1. When the respondents were asked about the basic information regarding generic medicines, the majority gave incorrect answers for nine out of 12 questions (Table 2 and Figure 1).

Fisher's Exact test showed that there was no significant difference ( $p$-value $>0.05$ ) in physicians' knowledge (correct vs incorrect answers) according to their gender (Table 2). The Fisher's Exact test also measured the difference in physician knowledge according to their years of experience. Two knowledge items were significantly different across years of physician experience. The elder generation physicians (with more than 5 years of experience) had significantly more incorrect answers about brand name medicines having fewer side effects and meeting higher safety measures compared to younger generation physicians (with less than 5 years of experience) (Table 2).

Most physicians had negative perceptions about generic medicines such as viewing generic medicines of low quality than brand name medicines (57.3\%) and thinking that they produce more side effects than brand name medicines (41.1\%) (Table 3). Most physicians (87.9\%) believed that they should be educated more about prices of medicines. In addition, more than half (54.8\%) perceived that low-cost medicines are not safe as high-priced medicines and $54.0 \%$ believed that it is easier to remember a brand name medicine. Regarding gender difference, significantly more male physicians agreed $(n=62$, $72.9 \%)$ compared to female that local companies are not following GMP guideline (table 3). Regarding years of experience, significantly more elder generation physicians (with more than 10 years of experience) believed that generic medicines produce more side effects than brand name medicines (Table 3).

A total of 12 questions were used to investigate the attitude of participating physicians towards generic medicines (Table 4). Although two-thirds (64.5\%) of the physicians were willing to prescribe low cost medicines, only half (51.6\%) reported they offer generic medicines to their patients. More than half (58.9\%) of the physicians were hesitant to prescribe low-cost medicines. Additionally, two-thirds (64.5\%) were not 
comfortable with the pharmacist replacing prescribed brands with generic medicines (Table 4). On the other hand, no significant difference ( $p$-value $>0.05$ ) in physicians' attitudes according to their gender.

According to the years of experience, the elder generation physicians (with more than 10 years of experience) were significantly less affected by socioeconomic status of patients when prescribe medications compared to physicians with $\leq 10$ years of experience. Similarly, the prescribing of physicians with experience longer than 10 years were significantly less affected by patient's demand (Table 4).

On the other hand, most physicians had negative perceptions and attitudes toward locally manufactured medicines (Figure 2). They believed that local medicines are less effective and have lower quality compared to brand medicines. Thus, they prescribe brand medicines for most cases. However, the majority physicians agreed that local medicines are more affordable than brand name ones (Figure 2).

\section{Discussion}

According to the study findings, there were gaps in the physician knowledge of generic medicines. Incorrect information was common among physicians about the safety, efficacy and quality of generic medicines. Out of 12 questions evaluating the knowledge of generic medicines, nine questions were answered incorrectly by the majority of physicians (Table 2 and Figure 1). The only three items that were answered correctly included that generic medicines are interchangeable with brand name medicines, generic medicines must be in the same dosage forms as brand medicines, and generic medicines are available in Iraq. These findings indicated a lack of physician knowledge about generic medicines which may have a negative impact on the confidence in generic drugs and consequently their prescribing. Cultural belief of low-cost products usually are less quality and effectiveness may also influence physician negative perceptions of generic medicines. Thus, the majority perceived that brand medicines are more effective and meet higher safety measures. This inadequate knowledge among physicians in the current study may be related to their coursework at Colleges of Medicines which did not adequately cover the topic of generic medicines in their curriculum. This reason was also reported by a previous study among final year medical students in Iraqi universities (4).

Similarly, Fabianio and colleagues found only $32.6 \%$ and $37.2 \%$ of Italian pediatricians have adequate and good knowledge of generic medicines respectively (13). In addition, only $2.3 \%$ to $4.6 \%$ of physicians in Malaysia correctly identified bioequivalence standards for generic medicines in recent studies (14)(15). In contrast, a study among general practitioners in Pakistan found that $71.8 \%$ of respondents had the correct definitions (11).
The elder generation physicians (with more than 5 years of experience) had significantly more incorrect answers about brand medicines to have fewer side effects and meet higher safety measures compared to younger generation physicians (with less than 5 years of experience). In contrast, a study among general practitioners in Nigeria found that $63.7 \%$ of respondents had at least average knowledge about the concept of generic medicine. Nigerian physicians with more than 10 years post-graduation experience have a higher knowledge mean score (16).

Regarding perceptions about generic medicines, most physicians had negative perceptions such as viewing generic medicines as lower quality and producing more side effects than brand name medicines. These negative physician perceptions may be because Iraqi pharmaceutical market contains so many generic drug products from wide range of countries (such as India, China, Turkey and Arabic countries) and some of these products are not officially registered and tested by Iraqi Ministry of Health ( $\mathrm{MOH})$. At the same time brand name medicines (from the U.S. and Europe) are also available in Iraqi drug market. Although brand name medicines are costly for Iraqi patients who pay out-of-pocket, physicians still prefer to prescribe well-known branded medicines. Colgan and colleagues conducted a systematic review of 52 articles about perceptions of generic medications among general population, doctors and pharmacists (8). The review found that a significant proportion of doctors hold negative perceptions of generic medicines such as generics as less effective, less safe, inferior in quality and more likely to cause side effects compared to their brand equivalents. More than a quarter of doctors believed that generic drugs are less effective and of poorer quality than brand name medications. A similar proportion of doctors had safety concerns about generics (8).

These findings are important as previous work has suggested that negative perceptions about generic medicines are major barriers to their acceptance and widespread usage (17). One of the interesting findings in our study was $87.9 \%$ of respondents agreed that doctors should be educated about the costs of medicine. Thus, we endorsed the suggestions of Cooke and colleagues, which highlighted the significance of a basic understanding of healthcare financing and costconsciousness among future medical practitioners (18).

The current study showed that older generation physicians (with more than 10 years of experience) were more likely to believe that generic medicines produce more side effects than brand medicines. These beliefs may be because younger physicians trained in an atmosphere where generics are used at increasing rates or may be related to perceptions of improved generic manufacturing processes (19). Similarly, an American study found that physicians older than 55 years of age have more than three times the negative perceptions to 
generics as younger doctors (19). The youngest physicians (under the age of 35) were significantly less likely to hold negative views regarding the quality and more likely to report a personal preference for generics or to recommend them to their families (19).

Regarding physician attitudes toward generic medicines, about two-thirds of the participants were not comfortable with pharmacist replacing prescribed brand with generic medicines (Table 4). Similarly, a previous Iraqi study showed hospital physicians only accept one-third of pharmacist recommendations (20). The physicians main concern about pharmacist replacing prescribed medicines is to dispense low quality generic medicines which may negatively impact patient clinical outcome. Thus, many physicians specify the trade name of their prescription items to avoid replacing with unknown low quality generics.

On the other hand, about two-thirds of the physicians were willing to prescribe low cost medicines; however, only about half of the physicians reported they prescribe generic medicines to their patients. This shows inconsistency between physician intention and the behavior of prescribing. Again, the possibility of therapeutic failure is a major concern among physicians about prescribing generic medicines. Before approving by Iraqi $\mathrm{MOH}$, generic medicines must undergo a rigorous registration process to ensure the quality, safety, efficacy and bioequivalence (21). Generally, there is a delay in registration process in $\mathrm{MOH}$. Similarly, a Nigerian study found that $82.7 \%$ of physicians are worried about the possibility of treatment failure and $74.9 \%$ would hesitate to prescribe generics from certain therapeutic classes (16). The issue of therapeutic failure is directly related to that of bioequivalence (22)(23). In a Moroccan study, $70 \%$ of respondents would prescribe generic drugs if bioequivalence to branded medicines is ascertained (24).

In the current study, $10.5 \%$ of respondents admitted their prescribing practices are influenced by gifts from pharmaceutical companies and $34.7 \%$ believed medical representatives were a good source of information. Accepting gifts and medical representatives may cause bias in selecting certain types of generic medicines over others. Providing gifts to doctors is common nowadays in private sector which can raise ethical concern and causes unfair competition between pharmaceutical companies. Similarly, a study among pharmacists and prescribers in Slovenia found only $15.5 \%$ of physicians admitted their prescribing behavior is influenced by pharmaceutical representatives (25). On the other hand, a Pakistani study found that $68 \%$ to $86 \%$ of the surveyed physicians obtained their knowledge of medicines from medical representatives (26).

In addition, most of the physicians (especially those with $\leq 10$ years of experience) agreed that patient socioeconomic status and patient demand influence their prescribing behavior (Table 4). Medications from the public (governmental) sector are mostly subsidized or free of charge, while in community pharmacies (private sector), patients pay out-of- pocket because health insurance is not common in Iraq (27). Some prescriptions may impose financial burden on people with limited income. Thus, some patients may ask their physicians to prescribe not highly expensive brand medicines. In the USA, being aware of patients with low socioeconomic status often influences the management plan of primary care physicians to fit their financial difficulties (28). Patient preferences can influence management decisions. For example, patients may prefer certain type of management despite it is unnecessary from an evidence basis. In a previous study, $71 \%$ of physicians stated that patient wishes had influenced their decision to admit patients to an intensive care unit (29). Similarly, general practitioners in Iceland were influenced by patients' pressure to prescribe antibiotics for unnecessary cases (30).

Iraqi physicians have similar negative perceptions toward locally manufactured products. The physicians consider national products as less effective and having lower quality compared to brand name medicines. The reason of these perceptions may be because they believe that national products are lacking the criteria of good manufacture products (GMP). These negative perceptions impact the physician prescriber behavior which is not in favor of national medicines as well (Figure 2).

The study had some limitations. First, this study was conducted only in one governorate. Hence, the findings might not be possible to be generalized to the whole country. However, it can provide useful data for health policy makers to further improve the use of generic medicines by considering the physicians' perspectives.

\section{Conclusions}

In general, Iraqi physicians have negative perceptions and attitudes about generic and locally manufactured medicines. The physicians with greater clinical experience had more negative perception and attitudes towards the safety and efficacy of the generic medicine locally made in Iraq. Thus, awareness campaign would be needed to expand physician knowledge about generic medicines. 


\section{References}

1. Dunne S, Shannon B, Dunne C, Cullen W. A review of the differences and similarities between generic drugs and their originator counterparts, including economic benefits associated with usage of generic medicines, using Ireland as a case study. BMC Pharmacol Toxicol [Internet]. 2013;14:1-19.

2. Naga Raju K, Sudheer Babu I, Prathyusha S, Sunitha T, Jyothi R, Sandhya V. Comparing branded drugs to their generic equivalents by spectrophotometric methods. Int J Res Pharm Chem [Internet]. 2012;2(3):681-4. Available from: http://www.ijrpc.com/files/15-2113.pdf

3. Chong CP, Hassali MA, Bahari MB, Shafie AA. Evaluating community pharmacists' perceptions of future generic substitution policy implementation: a national survey from Malaysia. Health Policy (New York). 2010;94(1):68-75.

4. Sharrad AK, Hassali MA. Knowledge and perceptions of final year medical students in iraqi universities about generic medicines. J Bioequivalence Bioavailab. 2011;3(5):086-91.

5. Pawel L PK. Generic drugs : The benefits and risks of making the switch. World Health. 2010;59(11):63440.

6. Dunne SS, Dunne CP. What do people really think of generic medicines? A systematic review and critical appraisal of literature on stakeholder perceptions of generic drugs. BMC Med. 2015;13(1).

7. Shrank WH, Hoang T, Ettner SL, Glassman PA, Nair K, DeLapp D, et al. The Implications of Choice. Arch Intern Med. 2006;166(3):332.

8. Colgan S, Faasse K, Martin LR, Stephens MH, Grey A, Petrie KJ. Perceptions of generic medication in the general population, doctors and pharmacists: $\mathrm{A}$ systematic review. BMJ Open. 2015;5(12).

9. Qian J, Mishuk AU, Hansen RA. Does public perception bias lead to more frequent reporting of adverse events: branded vs generic drugs. Expert Opin Drug Saf [Internet]. 2018;17(8):753-6. Available from: https://doi.org/10.1080/14740338.2018.1503648

10. Sharrad AK, Hassali MA, Shafie AA. Generic medicines: Perceptions of physicians in Basrah, Iraq. Australas Med J. 2009;2(8):58-64.

11. Jamshed SQ, Ibrahim MIM, Hassali MAA, Masood I, Low BY, Shafie AA, et al. Perception and attitude of general practitioners regarding generic medicines in Karachi, Pakistan: A questionnaire based study. South Med Rev. 2012;5(1):22-30.
12. Ellen S. Kostera, Daphne Philberta, Liset van Dijkb, Jany Rademakersb, Peter A.G.M. Smetd, Marcel L. Bouvya, Marcia Vervloet. Recognizing pharmaceutical illiteracy in community pharmacy: Agreement between a practice-based interview guide and questionnaire based assessment. Res Social Adm Pharm. 2018 Sep;14(9):812-816.

13. Fabiano V, Mameli C, Cattaneo D, Delle Fave A, Preziosa $A$, Mele $G$, et al. Perceptions and patterns of use of generic drugs among Italian family pediatricians: first round results of a web survey. Health Policy (New York). 2012;104(3):247-52.

14. Chua GN, Hassali MA, Shafie AA, Awaisu A. A survey exploring knowledge and perceptions of general practitioners towards the use of generic medicines in the northern state of Malaysia. Health Policy (New York). 2010;95(2-3):229-35.

15. Kumar R, Hassali MA, Saleem F, Alrasheedy AA, Kaur $\mathrm{N}$, Wong $\mathrm{ZY}$, et al. Knowledge and perceptions of physicians from private medical centres towards generic medicines: A nationwide survey from Malaysia. J Pharm Policy Pract. 2015;8(1):1-13.

16. Joseph O Fadare, Adekunle O. Adeoti, Olufemii O. Desalu, Okezie O. Enwere, Aliyu M. Makusidi, Olayinka Ogunleye, Taofeek O. Sunmonu, Ilse Truter, Onyinye O Akunne BG. The prescribing of generic medicines in Nigeria: knowledge, perceptions and attitudes of physicians. Expert Review Pharmacoeconomics Outcomes Research. 2013;2731.

17. Stewart K, Alrasheedy A, Hassali A, Kong D, Aljadhey $\mathrm{H}$, Ibrahim MIBM, et al. Patient knowledge, perceptions, and acceptance of generic medicines: a comprehensive review of the current literature. Patient Intell. 2014;1.

18. Cooke M, Avorn J, Ray W. Cost Consciousness in Patient Care - What Is Medical Education's Responsibility? New England Journal of Medicine. 2010;1253-5.

19. Shrank WH, Liberman JN, Fischer MA, Girdish C, Brennan TA, Choudhry NK. Physician perceptions about generic drugs. Ann Pharmacother. 2011;45(1):31-8.

20. Al-Jumaili Ali Azeez, Jabri AM, Al-Rekabi MD, Abbood SK, Hussein AH. Physician acceptance of pharmacist recommendations about medication prescribing errors in Iraqi hospitals. Inov Pharm. 2016;7(3).

21. Al-Jumaili AA, Hussain SA, Sorofman B. Pharmacy in Iraq: history, current status, and future directions. Am J Heal Pharm. 2013;70(4):368-72.

22. Borgheini $G$. The bioequivalence and therapeutic efficacy of generic versus brand-name psychoative drugs. Clin Ther. 2003;25(6):1578-92. 
23. Le PC. Bioequivalence and generics of index drugs with narrow therapeutic margins. Press medicale (Paris, Fr 1983). 2010;39(2):169-76.

24. Zaoui S, Hakkou F, Filali H. Generic drugs in Morocco: survey of physicians. Therapie. 2011;66(6):499-506.

25. Kersnik J, Peklar J. Attitudes of Slovene general practitioners towards generic drug prescribing and comparison with international studies. J Clin Pharm Ther. 2006;31(6):577-83.

26. Riaz H, Godman B, Hussain S, Malik F, Mahmood S, Shami A, et al. Prescribing of bisphosphonates and antibiotics in Pakistan: challenges and opportunities for the future. J Pharm Heal Serv Res. 2015;6(2):11121.

27. Ali A. Al-Jumaili, Ahmed Hashim, Muhammed AlRekabi ,Saba and Erika Ernst. Pattern and Total Cost of Antibiotics Consumption in an Iraqi Province. International Journal of Pharmacy Practice. 2017 Feb;25(1):81-88.

28. Bernheim SM, Ross JS, Krumholz HM, Bradley EH. Influence of patients' socioeconomic status on clinical management decisions: A qualitative study. Ann Fam Med. 2008;6(1):53-9.

29. Escher M, Perneger T V, Chevrolet J. About Admission To Intensive Care. Bmj. 2004;329(August).

30. Petursson P. GPs' reasons for "non-pharmacological” prescribing of antibiotics: A phenomenological study. Scand J Prim Health Care. 2005;23(2):120-5. 
Table 1: The demographics and professional characteristics of the physicians

\begin{tabular}{|c|c|c|c|c|}
\hline \multicolumn{2}{|l|}{ Item } & Subcategory & $\begin{array}{c}\text { Frequency } \\
\text { (N) }\end{array}$ & $\%$ \\
\hline \multirow{2}{*}{\multicolumn{2}{|c|}{ Gender }} & Male & 85 & 68.5 \\
\hline & & Female & 39 & 31.5 \\
\hline \multirow{3}{*}{\multicolumn{2}{|c|}{ Experience Years }} & $1-5$ & 27 & 21.8 \\
\hline & & $5-10$ & 47 & 37.9 \\
\hline & & $>10$ & 50 & 40.3 \\
\hline \multirow{3}{*}{\multicolumn{2}{|c|}{ Credential }} & GP & 28 & 22.6 \\
\hline & & Specialist & 82 & 66.1 \\
\hline & & Consultant & 14 & 11.3 \\
\hline \multirow{7}{*}{\multicolumn{2}{|c|}{ Specialty }} & GP & 28 & 22.6 \\
\hline & & Cardiologist & 32 & 25.8 \\
\hline & & Gastroenterologist & 11 & 8.9 \\
\hline & & Dermatologist & 3 & 2.4 \\
\hline & & Gynecologist & 10 & 8.1 \\
\hline & & Pediatrician & 7 & 5.6 \\
\hline & & Internal Medicine & 33 & 26.6 \\
\hline Item & Minimum & Maximum & Mean & Std. Deviation \\
\hline Age & 28 & 62 & 39.2 & 6.1 \\
\hline Number of patients seen/day & 3 & 40 & 10.2 & 6.2 \\
\hline Medical representative visits/week & 0 & 20 & 3.4 & 3.3 \\
\hline
\end{tabular}

$\mathrm{GP}=$ general practitioner

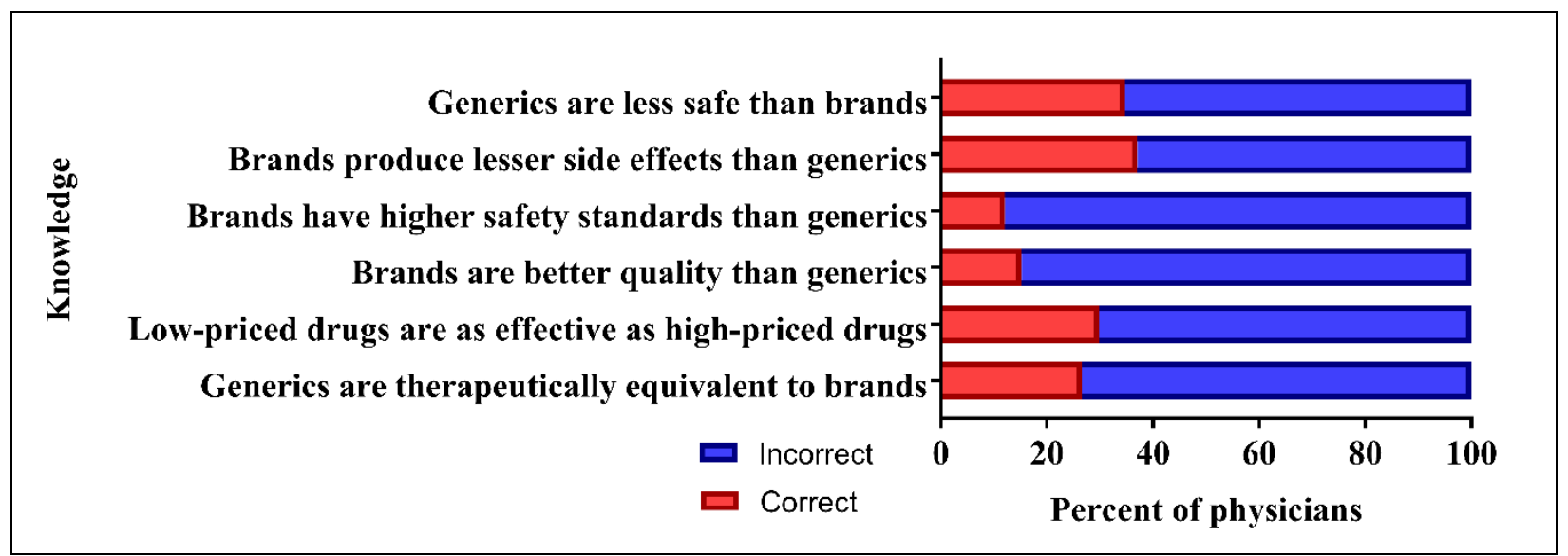

Figure 1: Selected knowledge items with majority of incorrect answers

Brands=brand name medicines; Generics=generic medicines. 
Table 2: The knowledge of generic medicines among physicians

\begin{tabular}{|c|c|c|c|c|c|}
\hline & \multirow[b]{2}{*}{ Knowledge item } & \multicolumn{2}{|l|}{$\mathbf{N}(\%)$} & \multicolumn{2}{|c|}{$\begin{array}{l}\text { Fisher's Exact Test } \\
\text { (P-value) }\end{array}$} \\
\hline & & $\begin{array}{c}\text { Correct } \\
\text { Responses }\end{array}$ & $\begin{array}{l}\text { Incorrect } \\
\text { Responses }\end{array}$ & Gender & Experience $\underset{*}{*}$ \\
\hline 1 & Generic medicines are copy of brand name medicines & $40(32.3)$ & $84(67.7)$ & 0.816 & 0.299 \\
\hline 2 & $\begin{array}{l}\text { Generic medicines are interchangeable with brand } \\
\text { name medicines }\end{array}$ & $86(69.4)$ & $38(30.6)$ & 0.982 & 0.377 \\
\hline 3 & $\begin{array}{l}\text { Generic medicines are manufactured after the patent } \\
\text { expiry of originator/innovator }\end{array}$ & $45(36.3)$ & $79(63.7)$ & 0.652 & 0.190 \\
\hline 4 & $\begin{array}{l}\text { Generic medicines are therapeutically equivalent to } \\
\text { brand name medicines }\end{array}$ & $33(26.6)$ & $91(73.4)$ & 0.166 & 0.754 \\
\hline 5 & $\begin{array}{l}\text { Low-priced medicines are as effective as high-priced } \\
\text { medicines }\end{array}$ & $37(29.8)$ & $87(70.2)$ & 0.138 & 0.123 \\
\hline 6 & $\begin{array}{l}\text { Brand name medicines are better quality than generic } \\
\text { medicines }\end{array}$ & $19(15.3)$ & $105(84.7)$ & 0.581 & 0.559 \\
\hline 7 & $\begin{array}{l}\text { Generic medicines must be in the same dosage form } \\
\text { (such as tablet, capsule) as brand name medicines }\end{array}$ & $86(69.4)$ & $38(30.6)$ & 0.615 & 0.270 \\
\hline 8 & $\begin{array}{l}\text { Brand name medicines are required to meet higher } \\
\text { safety standards than generic medicine }\end{array}$ & $15(12.1)$ & 109 (87.9) & 0.617 & $0.002 *$ \\
\hline 9 & $\begin{array}{l}\text { Brand name medicines produce lesser side effects than } \\
\text { generic medicines }\end{array}$ & $46(37.1)$ & $78(62.9)$ & 0.960 & $0.009 *$ \\
\hline 10 & $\begin{array}{l}\text { Generic medicines are less safe than brand name } \\
\text { medicines }\end{array}$ & $43(34.7)$ & $81(65.3)$ & 0.338 & 0.127 \\
\hline 11 & $\begin{array}{l}\text { Only those generic medicines are safe which are made } \\
\text { by some local reputable manufacturers }\end{array}$ & $43(34.7)$ & $81(65.3)$ & 0.536 & 0.502 \\
\hline 12 & Generic medicines are available in the market of Iraq & $107(86.3)$ & $17(13.7)$ & 0.264 & 0.394 \\
\hline
\end{tabular}

* Experience: 3 categories :(1-5), (6-10), (>10) years.

*Significant (P-value <0.05) according to Fisher's Exact Test. The answers for these questions were:

yes, no, I do not know. "I do not know' answers were considered incorrect. 
Table 3: The perceptions of participating physicians about generic medicines

\begin{tabular}{|c|c|c|c|c|c|c|}
\hline \multirow{2}{*}{\multicolumn{2}{|c|}{ Perception item }} & \multicolumn{3}{|c|}{ N (\%) } & \multicolumn{2}{|c|}{$\begin{array}{c}\text { Fisher's Exact Test } \\
\text { (P-value) }\end{array}$} \\
\hline & & Disagree & Neutral & Agree & Gender & Experience* \\
\hline 1 & $\begin{array}{l}\text { I view generic medicines of low quality than } \\
\text { brand name medicines }\end{array}$ & $28(22.6)$ & $25(20.2)$ & $71(57.3)$ & 0.867 & 0.931 \\
\hline 2 & $\begin{array}{l}\text { I think generic medicines produce more side } \\
\text { effects than brand name medicines }\end{array}$ & 49 (39.5) & $24(19.4)$ & $51(41.1)$ & 0.197 & $0.008^{*}$ \\
\hline 3 & $\begin{array}{l}\text { I believe low-cost medicines are as safe as } \\
\text { high-priced medicines }\end{array}$ & $68(54.8)$ & $30(24.2)$ & $26(21.0)$ & 0.336 & 0.486 \\
\hline 4 & $\begin{array}{l}\text { I believe that multinational products are of } \\
\text { good quality than local company products }\end{array}$ & $34(27.4)$ & $22(17.7)$ & $68(54.8)$ & 0.295 & 0.590 \\
\hline 5 & $\begin{array}{l}\text { I believe that my prescribing decision is } \\
\text { influenced by medical representatives }\end{array}$ & $55(44.4)$ & $32(25.8)$ & $37(29.8)$ & 0.603 & 0.239 \\
\hline 6 & $\begin{array}{l}\text { I believe that all the local companies in Iraq } \\
\text { are not following Good Manufacturing } \\
\text { Practices (GMP) guidelines as multinationals }\end{array}$ & 22 (17.7) & 21 (16.9) & $81(65.3)$ & $0.016^{*}$ & 0.334 \\
\hline 7 & $\begin{array}{l}\text { I view few local companies as reputable } \\
\text { generic medicine manufacturers }\end{array}$ & $33(26.6)$ & $44(35.5)$ & 47 (37.9) & 0.179 & 0.501 \\
\hline 8 & $\begin{array}{l}\text { I believe that doctors should be educated } \\
\text { more about prices of medicines }\end{array}$ & $8(6.5)$ & $7(5.6)$ & 109 (87.9) & 0.154 & 0.707 \\
\hline 9 & $\begin{array}{l}\text { I believe that doctors should be given } \\
\text { incentives to write generic names }\end{array}$ & $58(46.8)$ & 21 (16.9) & $45(36.3)$ & 0.454 & 0.064 \\
\hline 10 & $\begin{array}{l}\text { I believe that generic medicines are only } \\
\text { meant for poor }\end{array}$ & $65(52.4)$ & $27(21.8)$ & $32(25.8)$ & 0.762 & 0.502 \\
\hline 11 & $\begin{array}{l}\text { I think that confidence should be built in the } \\
\text { patient about the low-cost medicines }\end{array}$ & $18(14.5)$ & $38(30.6)$ & $68(54.8)$ & 0.691 & 0.677 \\
\hline 12 & $\begin{array}{l}\text { I believe that it is easier to remember a brand } \\
\text { name medicine }\end{array}$ & $30(24.2)$ & $27(21.8)$ & $67(54.0)$ & 0.487 & $0.002^{*}$ \\
\hline
\end{tabular}

* Experience: (1-5); (6-10); (>10) years.

*Significant (P-value $<0.05$ ) according to Fisher's Exact Test.

$\mathrm{GMP}=$ Good manufactured practice. 
Table 4: The attitude of participating physicians towards generic medicines

\begin{tabular}{|l|l|l|l|l|l|l|}
\hline & \multicolumn{2}{|c|}{ Attitude item } & \multicolumn{3}{|c|}{ N (\%) } & \multicolumn{2}{l|}{ Fisher's Exact Test ( P-value) } \\
\hline & \multicolumn{1}{|c|}{ Disagree } & Neutral & Agree & Gender & Experience* \\
\hline 1 & $\begin{array}{l}\text { I wish to prescribe low cost medicines in my } \\
\text { practice }\end{array}$ & $16(12.9)$ & $28(22.6)$ & $80(64.5)$ & 0.577 & 0.139 \\
\hline 2 & $\begin{array}{l}\text { I am concern about the therapeutic failures } \\
\text { that are serious problems with some locally } \\
\text { manufactured medicines }\end{array}$ & $13(10.5)$ & $29(23.4)$ & $82(66.1)$ & 0.207 & 0.279 \\
\hline 3 & $\begin{array}{l}\text { I am hesitant to prescribe low-cost brands in } \\
\text { some specific therapeutic classes in my } \\
\text { practice }\end{array}$ & $16(12.9)$ & $35(28.2)$ & $73(58.9)$ & 0.924 & 0.054 \\
\hline 4 & $\begin{array}{l}\text { I feel that the socioeconomic condition of my } \\
\text { patient influences the prescription }\end{array}$ & $6(4.8)$ & $7(5.6)$ & $\mathbf{1 1 1}(89.5)$ & 0.799 & $\mathbf{0 . 0 1 7 *}$ \\
\hline 5 & $\begin{array}{l}\text { I am comfortable to prescribe products from } \\
\text { all local manufacturers }\end{array}$ & $62(50.0)$ & $31(25.0)$ & $31(25.0)$ & 0.570 & 0.504 \\
\hline 6 & $\begin{array}{l}\text { I feel that my personal experience with } \\
\text { medicines influence my prescribing decisions }\end{array}$ & $8(6.5)$ & $9(7.3)$ & $\mathbf{1 0 7}(\mathbf{8 6 . 3 )}$ & 0.694 & 0.739 \\
\hline 7 & $\begin{array}{l}\text { I feel that patient's demand of medicine } \\
\text { influences my prescription }\end{array}$ & $28(22.6)$ & $22(17.7)$ & $\mathbf{7 4}(59.7)$ & 0.614 & $\mathbf{0 . 0 3 7 *}$ \\
\hline 8 & $\begin{array}{l}\text { I feel that medical representative is a good } \\
\text { source of information for me }\end{array}$ & $52(41.9)$ & $29(23.4)$ & $43(34.7)$ & 0.828 & 0.532 \\
\hline 9 & $\begin{array}{l}\text { I feel that pharmaceutical companies' } \\
\text { premium offers (gifts) influence my } \\
\text { prescribing behavior }\end{array}$ & $98(79.0)$ & $13(10.5)$ & $13(10.5)$ & 0.735 & 0.429 \\
\hline 10 & $\begin{array}{l}\text { I feel a lack of quality check in locally } \\
\text { manufactured products }\end{array}$ & $15(12.1)$ & $33(26.6)$ & $76(61.3)$ & 0.960 & 0.825 \\
\hline 11 & $\begin{array}{l}\text { I am comfortable if the brand name medicine } \\
\text { in prescription is changed by pharmacist }\end{array}$ & $80(64.5)$ & $20(16.1)$ & $24(19.4)$ & 0.970 & 0.059 \\
\hline 12 & I offer my patients generic medicines & $14(11.3)$ & $46(37.1)$ & $64(51.6)$ & 0.185 & 0.249 \\
\hline
\end{tabular}

* Experience: (1-5); (6-10); (>10) years.

*Significant (P-value $<0.05$ ) according to Fisher's Exact Test.

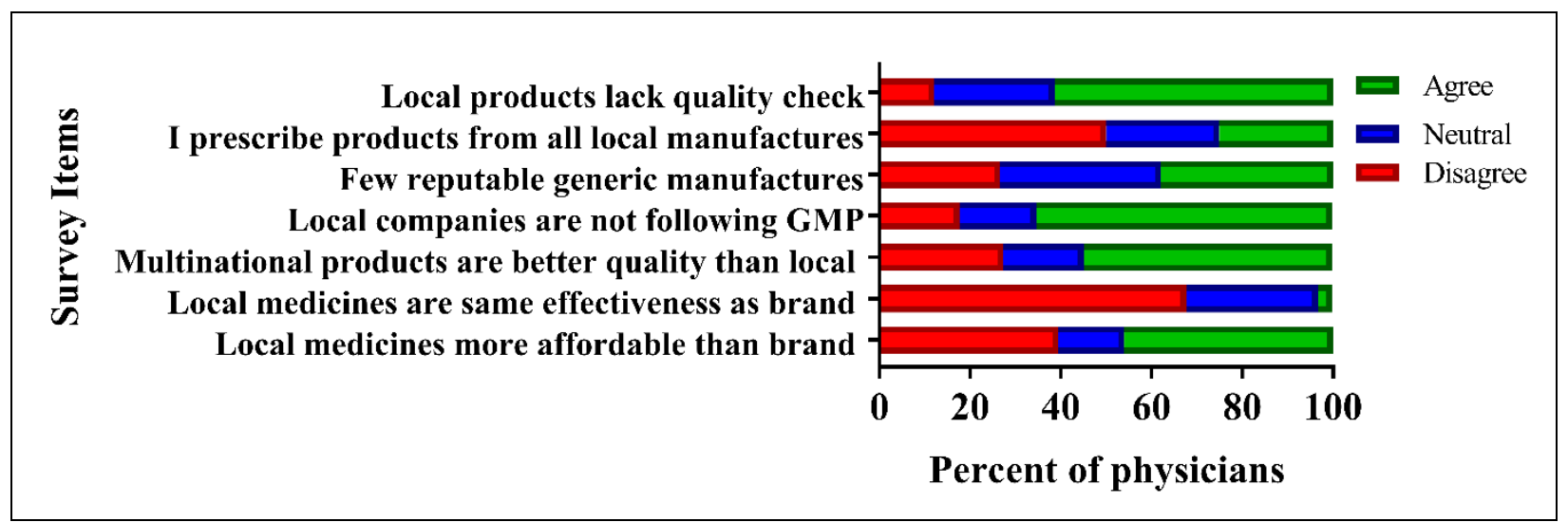

Figure 2: Perceptions and attitudes of physicians about locally manufactured medicines 